\title{
Anaerobic degradation of 1-methylnaphthalene by a member of the Thermoanaerobacteraceae contained in an iron-reducing enrichment culture
}

\author{
Sviatlana Marozava $\mathbb{D} \cdot$ Housna Mouttaki $\cdot$ Hubert Müller • Nidal Abu Laban • \\ Alexander J. Probst • Rainer U. Meckenstock
}

Received: 24 April 2017 / Accepted: 2 November 2017/Published online: 24 November 2017

(C) The Author(s) 2017. This article is an open access publication

\begin{abstract}
An anaerobic culture (1MN) was enriched with 1-methylnaphthalene as sole source of carbon and electrons and $\mathrm{Fe}(\mathrm{OH})_{3}$ as electron acceptor. 1-Naphthoic acid was produced as a metabolite during growth with 1-methylnaphthalene while 2-naphthoic acid was detected with naphthalene and 2-methylnaphthalene. This indicates that the degradation pathway of 1-methylnaphthalene might differ from naphthalene and 2-methylnaphthalene degradation in sulfate reducers. Terminal restriction fragment length polymorphism and pyrosequencing revealed that the
\end{abstract}

Electronic supplementary material The online version of this article (https://doi.org/10.1007/s10532-017-9811-z) contains supplementary material, which is available to authorized users.

\section{S. Marozava $\cdot$ H. Mouttaki}

Helmholtz Zentrum München, Institute of Groundwater Ecology, Ingolstädter Landstraße 1, 85764 Neuherberg, Germany

Present Address:

H. Mouttaki

Intrapore UG, Katernberger Str. 107, 45327 Essen, Germany

H. Müller · N. A. Laban · R. U. Meckenstock ( $\square)$

Biofilm Center, University of Duisburg-Essen,

Universitätsstr. 5, 41451 Essen, Germany

e-mail: rainer.meckenstock@uni-due.de

\section{A. J. Probst}

Group for Aquatic Microbial Ecology, Biofilm Center, University of Duisburg-Essen, Universitätsstr. 5,

41451 Essen, Germany culture is mainly composed of two bacteria related to uncultured Gram-positive Thermoanaerobacteraceae and uncultured gram-negative Desulfobulbaceae. Stable isotope probing showed that a ${ }^{13} \mathrm{C}$-carbon label from ${ }^{13} \mathrm{C}_{10}$-naphthalene as growth substrate was mostly incorporated by the Thermoanaerobacteraceae. The presence of putative genes involved in naphthalene degradation in the genome of this organism was confirmed via assembly-based metagenomics and supports that it is the naphthalene-degrading bacterium in the culture. Thermoanaerobacteraceae have previously been detected in oil sludge under thermophilic conditions, but have not been shown to degrade hydrocarbons so far. The second member of the community belongs to the Desulfobulbaceae and has high sequence similarity to uncultured bacteria from contaminated sites including recently proposed groundwater cable bacteria. We suggest that the grampositive Thermoanaerobacteraceae degrade polycyclic aromatic hydrocarbons while the Desulfobacterales are mainly responsible for $\mathrm{Fe}(\mathrm{III})$ reduction.

Keywords Polycyclic aromatic hydrocarbons . 1-methylnaphthalene - Thermoanaerobacteraceae . Desulfobulbaceae · Iron reduction · Synthrophic degradation 


\section{Introduction}

Polycyclic aromatic hydrocarbons (PAHs) are frequent contaminants in groundwater and marine sediments due to accidents during crude oil production, transportation or storage of mineral oil products. Among those, naphthalene and 2-methylnaphthalene are in the top 30 of frequently occurring emerging pollutants according to the European Environment Agency groundwater organic micropollutant database (Stuart et al. 2012). Although indigenous microbial communities are able to degrade these compounds, their low water solubility, the chemical stability of the aromatic ring, and adsorption to sediments make PAHs poorly bioavailable. Due to low solubility of oxygen in water, oxygen is quickly removed by aerobic bacteria in sediments and groundwater upon contamination with hydrocarbons. Therefore, anaerobic utilization of PAHs is the prevailing process in contaminated aquifers (Meckenstock et al. 2015; Folwell et al. 2016). Anaerobic biodegradation of PAHs can be coupled to sulfate and iron reduction, and methanogenesis whereas reports on denitrifying cultures were not reproducible, so far (Meckenstock et al. 2016). The best investigated PAH-degrading cultures to date contain sulfate reducers (Galushko et al. 1999; Meckenstock et al. 2000; Musat et al. 2009) belonging to Desulfobacteraceae within the Deltaproteobacteria (Meckenstock and Mouttaki 2011). Incorporation of ${ }^{13} \mathrm{C}$-bicarbonate by a marine, sulfate-reducing enrichment indicated that naphthalene might be carboxylated to 2-naphthoic acid (Zhang et al. 2012a). Recently, it has been proven in biochemical studies with the highly enriched sulfate-reducing enrichment culture N47 originating from groundwater that naphthalene is indeed activated via carboxylation to 2-naphthoic acid (Mouttaki et al. 2012). Degradation of 2-methylnaphthalene is initiated via fumarate addition with formation of naphthyl-2-methyl-succinic acid (Fig. 1) (Annweiler et al. 2000). Then, naphthyl-2-methyl-succinic acid is converted to 2 -naphthoic acid via several $\beta$-oxidation steps (Safinowski and Meckenstock 2004). 2-Naphthoic acid can be regarded as a central metabolite in the anaerobic degradation of naphthalene and 2-methylnaphthalene.

Ferric iron is a wide-spread electron acceptor in aquifers. Several pure cultures capable of biodegradation of monoaromatic hydrocarbons that have been isolated belong to Geobacteraceae (Lovley et al.
1993; Zhang and Young 1997; Coates et al. 2001; Nevin and Lovley 2002), Rodocyclaceae (Weelink et al. 2009), and Peptococcaceae (Kunapuli et al. 2010). Only recently, an iron-reducing, naphthalenedegrading enrichment culture has been described. It is dominated by members of the Peptococcaceae which can grow not only with naphthalene but also with 1-, and 2-methylnaphthalene as sole electron and carbon source (Kleemann and Meckenstock 2011).

Although both 1- and 2-methylnaphthalenes are readily degraded by aerobic cultures (Mahajan et al. 1994; Mueller-Spitz and Crawford 2014), anaerobic degradation of 1-methylnaphthalene has been reported so far only for an anaerobic sediment enrichment (Genthner et al. 1997) or sludge (Christensen et al. 2004) under methanogenic conditions and for an ironreducing enrichment N49 (Kleemann and Meckenstock 2011). In other studies, where 1-methylnaphthalene has been tested, growth was observed only on the isomer 2-methylnaphthalene (Meckenstock et al. 2000; Galushko et al. 2003; Musat et al. 2009). Therefore, 1-methylnaphthalene has been considered to be less susceptible to biodegradation and the degradation pathway of 1-methylnaphthalene remains unclear.

Here, we report on an iron-reducing enrichment which was cultivated with 1-methylnaphthalene as sole carbon and electron source. We performed stable isotope probing and assembly-based metagenome analysis of the $1 \mathrm{MN}$ culture grown with ${ }^{13} \mathrm{C}_{10^{-}}$ naphthalene. The goal was to identify the PAHdegrading microorganisms in the culture and to obtain insight in the degradation process of 1-methylnaphthalene.

\section{Materials and methods}

Growth of enrichment culture

The 1-methylnapthalene-degrading culture $1 \mathrm{MN}$ was enriched from contaminated soil at a former coal gasification site in Gliwice, Poland with 1-methylnaphthalene as sole carbon source. 1-methylnaphthalene was provided as absorbed to a resin Amberlite XAD-7 (Morasch et al. 2001) and $50 \mathrm{mM} \mathrm{Fe}(\mathrm{OH})_{3}$ was added as electron acceptor. $\mathrm{Fe}(\mathrm{OH})_{3}$ was synthesized via neutralizing a $0.4 \mathrm{M}$ solution of $\mathrm{FeCl}_{3}$ to a $\mathrm{pH}$ of 7 with $\mathrm{NaOH}$ (Lovley and Phillips 1988). The 


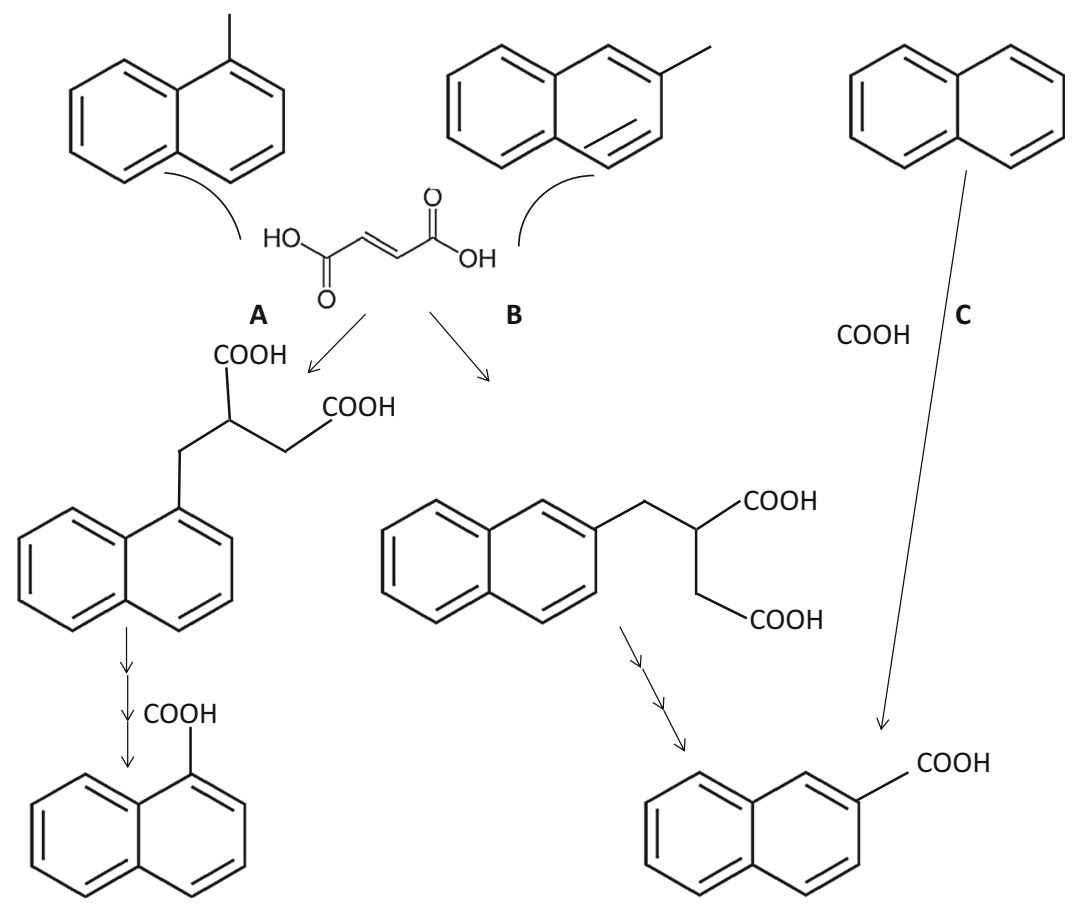

Fig. 1 Activation mechanisms proposed for biodegradation of 1-methylnaphthalene (a) and 2-methylnaphthalene (b) via fumarate addition with subsequent formation of 1-naphthoic acid (a) and 2-naphthoic acid (b); and biodegradation

enrichment culture was cultivated in fresh water medium (Widdel and Bak 1991) (pH 7.2) and was reduced with $0.7 \mathrm{mM} \mathrm{Na}_{2} \mathrm{~S}$. $0.24 \mathrm{mM}$ of the humic acid analogue 9,10-anthraquinone-2,6-disulfonic acid disodium salt was added in order to facilitate $\mathrm{Fe}(\mathrm{OH})_{3}$ reduction. Before carrying out the main experiments, the sediment-free cultures were transferred with $10 \%$ inoculum every 3 months over 6 years and cultivated in $100 \mathrm{ml}$ serum bottles containing $90 \mathrm{ml}$ of medium. In such a way, any carbon substrates associated with the source of isolation were eliminated from the culture medium.

In order to obtain a pure culture, serial dilutions to extinction were performed: inoculum was serially diluted in culture bottles up to $10^{12}$ dilution where no cells were expected to be. However, no pure cultures were obtained after.

For metabolite analyses, cultures were cultivated in 11 bottles containing $900 \mathrm{ml}$ medium. 1-Methylnaphthalene, 2-methylnaphthalene, or naphthalene, were dissolved as $50 \mathrm{mM}$ solution in $2,2,4,4,6,8,8$ - of napthathalene (c) via carboxylation with formation of 2-naphthoic acid

heptamethylnonane (HMN). $1.4 \mathrm{ml}$ from a $50 \mathrm{mM}$ stock solution was added per $100 \mathrm{ml}$ of culture medium.

For electron balance experiments, $10 \mu \mathrm{l}$ (approximately, $11 \mathrm{mg}$ or $0.08 \mathrm{mM}$ ) of 1-methylnaphthalene was added with a glass syringe directly into the culture bottles containing $900 \mathrm{ml}$ autoclaved medium. Solubility of 1-methylnaphthalene at $25^{\circ} \mathrm{C}$ is $25 \mathrm{mg} \mathrm{l}^{-1}$ (Linstrom and Mallard 2001) allowing for total dissolution of the 1-methylnaphthalene added. Bottles were shaken for three days at room temperature to fully dissolve the 1-methylnaphthalene prior to inoculation and no visible droplets of 1-methylnaphthalene remained in the liquid medium.

To test for sulfur cycling involved in iron reduction, culture $1 \mathrm{MN}$ was grown in media containing $30 \mathrm{mM}$ of $\mathrm{Fe}(\mathrm{OH})_{3}$ reduced with $0.7 \mathrm{mM} \mathrm{Na}_{2} \mathrm{~S}$ with $30 \mathrm{mM}$ elemental sulfur in the absence of 1-methylnaphthalene and HMN. After 3 consecutive transfers, the culture was inoculated into freshwater medium with $30 \mathrm{mM} \mathrm{Fe}(\mathrm{OH})_{3}$ as electron acceptor, $30 \mathrm{mM}$ elemental sulfur as electron donor, and $0.7 \mathrm{mM} \mathrm{Na}_{2} \mathrm{~S}$ as a 
reducing agent in the absence of any organic carbon source. Sulfate, sulfide, and Fe(II) concentrations were monitored weekly and compared to abiotic controls.

Stable isotope probing experiments were performed with fully labelled ${ }^{13} \mathrm{C}_{10}$-naphthalene or ${ }^{12} \mathrm{C}_{10}$-naphthalene (99\% atoms Sigma-Aldrich) dissolved in HMN with final concentration of 0.05 and $0.07 \mathrm{mM}$, respectively. $10 \%$ of inoculum from cultures pre-grown with ${ }^{12} \mathrm{C}_{10}$-naphthalene was added into $200 \mathrm{ml}$ serum bottles filled with $170 \mathrm{ml}$ of medium. Each condition was performed in duplicates. Growth was monitored via measuring $\mathrm{Fe}(\mathrm{II})$ production. For DNA extraction, each bottle with ${ }^{13} \mathrm{C}_{10}$-naphthalene was harvested completely when approximately $0.3 \mathrm{mM} \mathrm{CO} \mathrm{CO}_{2}$ equivalent to consumption of $0.03 \mathrm{mM}$ naphthalene was produced in the 1st and 2nd bottle after 72 and 97 days, respectively (Fig. 2). Each control bottle with ${ }^{12} \mathrm{C}_{10^{-}}$ naphthalene was harvested twice at the same sampling times of 72 and 97 days.

Chemical analysis

$\mathrm{Fe}(\mathrm{II})$ was determined by the ferrozine assay according to (Braunschweig et al. 2012) using a Cary 50 Bio UV-Vis photometer (Varian, Darmstadt, Germany) at a wavelength of $508 \mathrm{~nm}$. Sulfate was measured by ion chromatography on a Dionex Aquion system (Thermo Fisher Scientific, Dreieich, Germany). Sulfide was determined by the methylene-blue method which was downscaled to 96-well-plate format (Cline 1969; Müller et al. 2016).

1-Methylnaphthalene, 1-, and 2-naphthoic acids concentration was measured by HPLC (Shimadzu, Japan) on a PFP Kinetex column $(75 \times 4.6 \mathrm{~mm})$ (Phenomenex Inc., USA). For 1-methylnaphthalene detection, a 40-60\% gradient of acetonitrile in deionized water was applied at a flow rate of $1 \mathrm{ml} \mathrm{min}^{-1}$ (UV detection at $223 \mathrm{~nm}$ ). 1-, and 2-naphthoic acids were separated by isocratic elution with $1 \%$ acetic acid in deionized water (solvent $\mathrm{A}$ ) and acetonitrile (sol-

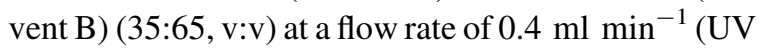
detection at $224 \mathrm{~nm}$ ). Column temperature was set to $30{ }^{\circ} \mathrm{C}$.

\section{Metabolite analysis}

For metabolite analysis, $300 \mathrm{ml}$ aliquots were taken from cultures, adjusted to $\mathrm{pH} 12$ with $1 \mathrm{~N} \mathrm{NaOH}$ and stirred for $30 \mathrm{~min}$ to hydrolyze possible thioester bonds. Samples were acidified to $\mathrm{pH}<2$ with $12 \mathrm{~N}$ $\mathrm{HCl}$, extracted three times with ethylacetate (1:1 ratio of sample to ethylacetate), and filtered through anhydrous sodium sulfate to remove traces of water. The collected ethylacetate phase was concentrated in a vacuum rotator at $65^{\circ} \mathrm{C}$ to a volume of $2 \mathrm{ml}$ and further evaporated under a stream of nitrogen gas to $1 \mathrm{ml}$. Samples were derivatized with $250 \mu \mathrm{l}$ of N,Obis-(trimethylsilyl)trifluoroacetamide (BSTFA) at $65{ }^{\circ} \mathrm{C}$ for $30 \mathrm{~min}$.

The detection of the metabolites was performed with GC-MS (Agilent Technologies, GC System 7890A) equipped with a DB-5 column $(0.25 \mu \mathrm{m}$ film thickness, $0.25 \mathrm{~mm}$ i.d., $30 \mathrm{ml}$ length, Agilent Technologies, USA). Sample injection was splitless $(1 \mu \mathrm{l})$, and the flow rate of the helium carrier gas was $1.48 \mathrm{ml} \mathrm{min}^{-1}$. The oven temperature was $80{ }^{\circ} \mathrm{C}$ for $5 \mathrm{~min}$, then ramped at a rate of $20{ }^{\circ} \mathrm{C} \mathrm{min}{ }^{-1}$ to $230{ }^{\circ} \mathrm{C}$, and held for $10 \mathrm{~min}$. The injector temperature was $270{ }^{\circ} \mathrm{C}$.

For metabolite analysis with LC/MS/MS, $1 \mathrm{ml}$ of culture was centrifuged at $25,000 \times \mathrm{g}$ for $10 \mathrm{~min}$. $150 \mu \mathrm{l}$ aliquots of the resulting supernatants were transferred into small GC glass vials with a $200 \mu \mathrm{l}$ insert. Metabolite analysis was carried out by LC/MS/ MS on an Agilent 1200 series HPLC system coupled to an Applied Biosystems Q-Trap mass spectrometer equipped with a TurboSpray ionization source. Samples of $50 \mu 1$ were injected to a LiChroCART ${ }^{\circledR} 125-2$ Purospher $^{\circledR}$ STAR RP-18e $(5 \mu \mathrm{m})$ HPLC cartridge (Merck, Darmstadt, Germany). The column oven was set to $35{ }^{\circ} \mathrm{C}$. A gradient of $25-90 \%$ acetonitrile in $0.1 \%$ acetic acid was run at a flow rate of $0.3 \mathrm{ml}$ hour $^{-1}$ over $30 \mathrm{~min}$. The sample was infused into the mass spectrometer via multiple reaction monitoring in negative mode and an entrance potential of $-7 \mathrm{~V}$. The declustering potential was set to $-40 \mathrm{~V}$ and the collision energy was adjusted to $-13 \mathrm{~V}$.

\section{GC-C-IRMS analyses}

The total amount of ${ }^{13} \mathrm{CO}_{2}$ produced during degradation of ${ }^{13} \mathrm{C}_{10}$-naphthalene was determined by measuring the ${ }^{13} \mathrm{CO}_{2} /{ }^{12} \mathrm{CO}_{2}$ in the headspace of cultures cultivated with $0.05 \mathrm{mM}$ of ${ }^{13} \mathrm{C}_{10}$-naphthalene dissolved in HMN. The headspace sample $(500 \mu \mathrm{l})$ was added to a $10 \mathrm{ml}$ serum vial filled with helium, capped 
with blue butyl rubber stopper and stored at $4{ }^{\circ} \mathrm{C}$ until the analysis. The headspace samples were taken in triplicates. Gas samples $(100 \mu \mathrm{l})$ were taken from the storage bottles and injected manually into a $\mathrm{GC} / \mathrm{C} /$ IRMS system consisting of a TRACE GC Ultra gas chromatograph with split/splitless injector (GC) (Thermo Fischer Scientific, Milan, Italy) coupled to a Finnigan MAT 253 Isotope ratio mass spectrometer (IRMS) via Finnigan Gas combustion III interface (Thermo Fischer Scientific, Bremen, Germany). The GC was equipped with a RT-Q Plot ${ }^{\mathrm{TM}}$ column (30 m length, $0.32 \mathrm{~mm}$ internal diameter). Helium served as a carrier gas with a constant flow rate of $1.4 \mathrm{ml} \mathrm{min}^{-1}$. The initial oven temperature was set at $50{ }^{\circ} \mathrm{C}$ and ramped at a rate of $20^{\circ} \mathrm{C} \min ^{-1}$ to $230{ }^{\circ} \mathrm{C}$ and held for $5 \mathrm{~min}$. The ${ }^{13} \mathrm{CO}_{2}$ was calculated according to (Kleemann and Meckenstock 2011).

\section{ATP measurement}

ATP concentrations were used to evaluate live bacterial biomass in the enrichment culture according to the modified protocol of (Hammes et al. 2010). The measurements were performed with the BacTiterGlo $^{\mathrm{TM}}$ Microbial Cell Viability Assay kit (Promega, Germany). In order to remove iron from the samples, $1 \mathrm{ml}$ samples were spun down shortly for $10 \mathrm{~s}$ at $25,000 \times g$. In order to lyse the cells, $50 \mu \mathrm{l}$ of BacTiter$\mathrm{Glo}^{\mathrm{TM}}$ reagent were added to a $38{ }^{\circ} \mathrm{C}$ preheated supernatant. After $1 \mathrm{~min}$ of incubation in a thermomixer (Eppendorf, Germany) at $38{ }^{\circ} \mathrm{C}$ and $500 \mathrm{rpm}$, luminescence was measured on a luminometer (Glomax, Turner Biosystems, Sunnyvale, CA). The data were recorded in the form of relative light units (RLU) and transferred into ATP concentrations $(\mu \mathrm{M})$ via a calibration curve with ATP standards (Roche, Mannheim, Germany).

\section{Molecular analysis}

For DNA extraction, at least $10 \mathrm{ml}$ of samples were centrifuged for $10 \mathrm{~min}$ at $25,000 \times g$ and washed with $1 \times$ phosphate-buffered saline (PBS). Genomic DNA was extracted with a FastDNA Spin Kit for Soil (MP Biomedicals, Illkirch, France) and stored at $-20{ }^{\circ} \mathrm{C}$ until further analysis.

Bacterial 16S rRNA gene-targeted terminal restriction fragment length polymorphism (T-RFLP) fingerprinting was performed using Ba27f-FAM/907r primers. FAM-labelled amplicons were generated as described in (Pilloni et al. 2011), digested with the restriction enzyme MspI (Promega, Mannheim, Germany) and separated by capillary electrophoresis on ABI 3730 48-capillary sequencer as described in (Lueders et al. 2006).

Cultures which were cultivated for 1 month and showed bacterial activity via AQDS reduction (visual observation of yellow color) with 1-methylnaphthalene dissolved in HMN were used for pyrosequencing analysis. Barcoded amplicons for multiplexing were prepared with the primers Ba27f $\left(5^{\prime}\right.$-aga gtt tga tcm tgg ctc ag- $\left.3^{\prime}\right)$ and Ba519r ( $5^{\prime}$-tat tac cgc ggc kgc $\operatorname{tg}-3^{\prime}$ ) (Lane 1991) extended as amplicon fusion primers with respective primer A or B adapters, key sequence and multiplex identifiers (MID). Amplicon pyrosequencing on a 454 GS FLX Titanium system (Roche, Penzberg, Germany) and pyrotag data handling were performed according to (Pilloni et al. 2012). The generated data were assembled to contigs via the SEQMAN II software (DNAStar, Madison, WI), using forward- and reverse-reads, as described in (Pilloni et al. 2011). Created contigs were used for in silico T-RF prediction by TRiFLe (Junier et al. 2008). All assembled contigs from this study were deposited with GenBank under the accession numbers KY417998-KY418001. Classification of created contigs was performed with the RDP naïve Bayesian Classifier (Wang et al. 2007). Phylogenetic trees were created with the MEGA version 6 software using a maximum likelihood method (Hall 2013).

\section{Assembly-based metagenomics}

For metagenome sequencing, we used a subsample of DNA extracted from culture $1 \mathrm{MN}$ grown with ${ }^{13} \mathrm{C}_{10^{-}}$ naphthalene and harvested after 97 days of cultivation. The same sample was also used for the gradient centrifugation of the SIP experiments. Library preparation and paired-end Illumina HiSeq sequencing (read length $150 \mathrm{bp}$ ) were performed at GATC (Konstanz, Germany). Quality filtered reads [bbduck (http://jgi.doe.gov/data-and-tools/bbtools/) followed by SICKLE (Version 1.21, https://github.com/najoshi/ sickle)] were assembled using metaSPADES version 3.10.1 using default settings (Nurk et al. 2017). Genes were predicted using prodigal in the meta mode (-p meta) (Hyatt et al. 2010). Scaffolds were classified against UniRef100 (Suzek et al. 2007) using diamond 
blastp (Buchfink et al. 2015) by retrieving the taxonomy of the best blast hit for each protein of the scaffolds (e-value $10 \mathrm{E}-5$ ) followed by the calculation of the lowest taxonomic rank that covered at least $50 \%$ of the proteins present on the scaffold. Proteins were screened for naphthyl-2-methylsuccinate synthase (NmsA) and naphthalene carboxylase genes using diamond blastp (Buchfink et al. 2015) using previously published sequences retrieved from the non-redundant NCBI protein database as a template. Scaffolds carrying genes of interest were checked manually for scaffolding errors by mapping reads (Langmead and Salzberg 2012); default settings followed by visual inspection.

Gradient centrifugation of extracted labeled and unlabeled DNA of SIP experiment

The DNA harvested from labelled and control experiments was quantified by Quant-iT PicoGreen dsDNA quantification kit (Invitrogen, Paisley, UK). At least $600 \mathrm{ng}$ of DNA was loaded on a gradient buffer of $\mathrm{CsCl}$ (average density $1.71 \mathrm{~g} \mathrm{ml}^{-1}$, Calbiochem, Merck, Darmstadt, Germany) in gradient buffer (0.1 M Tris- $\mathrm{HCl}$ at $\mathrm{pH} 8,0.1 \mathrm{M} \mathrm{KCl}, 1 \mathrm{mM}$ EDTA) and centrifuged $\left(180,000 \times g\right.$, at $20{ }^{\circ} \mathrm{C}$ for $\left.>36 \mathrm{~h}\right)$ as described in detail in (Lueders et al. 2004). The gradient centrifugation was performed in $5.1 \mathrm{ml}$ polyallomer quick seal tubes in a VTI 65.2 vertical rotor using a Centrikon T-2190 centrifuge (Kontron Instruments, Milano, Italy). The steps after centrifugation were performed according to (Lueders 2010). Briefly, each gradient was divided into 13 equal fractions with 'heavy' DNA at the bottom and 'light' DNA at the top of the tubes using a Perfusor V syringe pump (Braun, Melsungen, Germany). Aliquots of $100 \mu \mathrm{l}$ were used to determine the density of each gradient fraction using an AR200 digital refractometer (Reichert Inc., Depew, NY, USA). DNA was retrieved from each fraction with polyethylene glycol precipitation, washed in $70 \%$ ethanol and re-eluted in $30 \mu \mathrm{l}$ elution buffer (Qiagen, Hilden, Germany). Bacterial 16S rRNA genes were quantified via qPCR from each precipitated fraction as described in (Kunapuli et al. 2007). Terminal restriction fragment length polymorphism (T-RFLP) fingerprinting was done for the six fractions with the most of DNA ( $97 \%$ of all recovered DNA).

\section{Results}

Degradation of 1-methylnaphthalene and other carbon sources

The iron-reducing culture $1 \mathrm{MN}$ was enriched from contaminated soil with 1-methylnaphthalene. After approximately 10 transfers, regular T-RFLP fingerprinting showed a stable microbial community consisting of three major tRFs at 149, 160, and $215 \mathrm{bp}$. The culture was routinely cultivated with 1-methylnaphthalene dissolved in 2,2,4,4,6,8,8-heptamethylnonane (HMN). Besides 1-methylnaphthalene degradation (Fig. 2a), the culture grew with the following substrates: 2-methylnaphthalene, naphthalene, 1- and 2-naphthoic acids (Table 1). The culture growth was monitored via analysis of Fe(II) production as well as visual inspection of the development of yellow color due to biological AQDS reduction. When nitrate or sulfate were used as electron acceptors instead of $\mathrm{Fe}(\mathrm{OH})_{3}$ with 1-methylnaphthalene as a carbon source, no bacterial growth was observed as there was no change in optical density over the course of cultivation. No AQDS reduction was observed when HMN only was provided without any of the above-mentioned carbon sources. No degradation of methylnaphthalenes in uninoculated bottles with $\mathrm{Fe}(\mathrm{OH})_{3}$ was detected. For example, Fig. 2a shows that in abiotic control there was no decrease in 1-methylnaphthalene concentration as well as no $\mathrm{Fe}(\mathrm{II})$ production over incubation time.

To determine the electron balance, the culture was transferred to medium with $0.08 \mathrm{mM}$ 1-methylnaphthalene dissolved in the aqueous phase. The degradation of 1-methylnaphthalene has occurred in two stages. In the first long stage, it took 138 days to degrade $0.021 \mathrm{mM}$ of 1-methylnaphthalene and produce 3.5 and $1.6 \mathrm{mM}$ of $\mathrm{Fe}(\mathrm{II})$. Such a long phase could be explained by adaptation of bacterial cells to relatively high concentration of 1-methylnaphthalene in the water as the pre-culture has been cultivated in the medium where 1-methylnaphhtalene has been dissolved in HMN phase. The second stage of degradation has been characterized by consumption of $0.06 \mathrm{mM}$ of 1-methylnaphthalene within 91 days and production of 9.9 and $8.2 \mathrm{mM}$ of $\mathrm{Fe}$ (II) (Fig. 2a). According to stoichiometric calculation (Eq. 1), $0.08 \mathrm{mM}$ of 1-methylnaphthalene consumed would lead to the production of $4.5 \mathrm{mM}$ of $\mathrm{Fe}(\mathrm{II})$. However, 

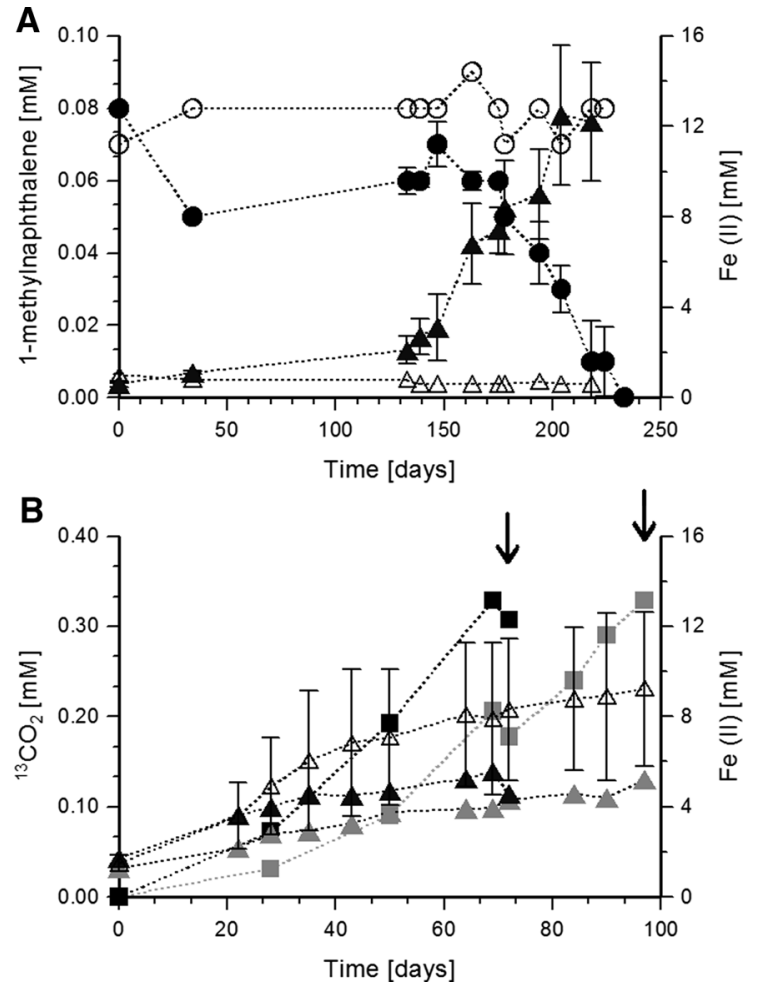

Fig. 2 Degradation of polycyclic aromatic hydrocarbons by enrichment culture $1 \mathrm{MN}$. a Growth of enrichment $1 \mathrm{MN}$ with 1-methylnaphthalene as carbon source and ferrihydrate as electron acceptor. Error bars represent standard deviation of two biological replicates. Filled circles, 1-methylnaphthalene concentrations in inoculated cultures; filled triangles, Fe(II) concentrations in inoculated cultures; open circles, 1-methylnaphthalene concentrations in abiotic control; open triangles, $\mathrm{Fe}(\mathrm{II})$ concentrations in abiotic control. b Growth with ${ }^{13} \mathrm{C}_{10^{-}}$ naphthalene as carbon source and ferrihydrate as electron acceptor. Arrows indicate the days of sampling for stable isotope probing-analysis after 72 days of incubation with ${ }^{13} \mathrm{C}_{10^{-}}$ naphthalene in early labeling experiment and 97 days of incubation with ${ }^{13} \mathrm{C}_{10}$-naphthalene in late labelling experiment. Error bars represent standard deviations of two replicates. Filled triangles, $\mathrm{Fe}(\mathrm{II})$ concentrations in cultures with ${ }^{13} \mathrm{C}_{10}$-naphthalene: black triangles-early harvested culture, grey triangles-late harvested culture; open triangles, $\mathrm{Fe}(\mathrm{II})$ concentrations in control cultures with ${ }^{12} \mathrm{C}_{10}$-naphthalene; squares, ${ }^{13} \mathrm{CO}_{2}$ concentration: black squares- ${ }^{13} \mathrm{CO}_{2}$ in early harvested culture; grey squares $-{ }^{13} \mathrm{CO}_{2}$ in late harvested culture

in this experiment 13.3 and $9.8 \mathrm{mM}$ of $\mathrm{Fe}(\mathrm{II})$ were produced. Even though 1-methylnaphthalene degradation alone does not explain this high amount of $\mathrm{Fe}(\mathrm{II})$ production, these results indicate that biological degradation of 1-methylnaphthalene was detected. In biological replicates, 1-methylnaphthalene has been
Table 1 List of the alternative substrates tested for growth of the 1-methylnaphthalene-degrading enrichment

\begin{tabular}{lll}
\hline Substrates tested & Concentration $(\mathrm{mM})$ & Growth \\
\hline 1-Methylnapthalene & 0.07 & + \\
2-Methylnapthalene & 0.07 & + \\
Naphthalene & 0.07 & + \\
1-Naphthoic acid & 0.1 & + \\
2-Naphthoic acid & 0.1 & + \\
1-Naphthyl acetate & 0.1 & - \\
2-Napthyl acetate & 0.1 & - \\
1-Napththol & 0.1 & - \\
2-Naphthol & 0.1 & - \\
Anthracene & 0.8 & - \\
Phenanthrene & 0.7 & - \\
Benzofuran-1 & 0.7 & - \\
Toluene & 0.5 & - \\
Benzoate & 1 & - \\
Puryvate & 1 & - \\
Hydroxybenzoate & 0.5 & \\
\hline
\end{tabular}

degraded completely while in abiotic control concentrations remained without change (Fig. 2a).

$$
\begin{aligned}
\mathrm{C}_{11} \mathrm{H}_{10}+54 \mathrm{Fe}(\mathrm{OH})_{3} \rightarrow & 11 \mathrm{HCO}_{3}^{-}+54 \mathrm{Fe}^{2+} \\
& +32 \mathrm{H}_{2} \mathrm{O}+97 \mathrm{OH}^{-}
\end{aligned}
$$

This was further supported by cultivation with $0.05 \mathrm{mM}$ of ${ }^{13} \mathrm{C}_{10^{-}}$naphthalene dissolved in HMN to prove the mineralization to $\mathrm{CO}_{2}$ (Fig. 2b). In two replicate bottles, $0.3-0.34 \mathrm{mM}$ of ${ }^{13} \mathrm{CO}_{2}$ were produced after 72-97 days of cultivation (Fig. 2b). The amount of ${ }^{13} \mathrm{CO}_{2}$ produced equaled to $0.03-0.034 \mathrm{mM}$ of naphthalene consumed demonstrating a total oxidation to $\mathrm{CO}_{2}$ and clear indication of bacterial degradation of ${ }^{13} \mathrm{C}_{10}$-naphthalene. According to the stoichiometry of complete mineralization of naphthalene to $\mathrm{CO}_{2}$ (Eq. 2.), 0.03-0.034 mM of consumed naphthalene would require $1.44 \mathrm{mM}$ of $\mathrm{Fe}(\mathrm{III})$ reduction. However, 2.8-3.9 $\mathrm{mM}$ of $\mathrm{Fe}$ (II) was detected suggesting an electron recovery of over $200 \%$. 


$$
\begin{aligned}
\mathrm{C}_{10} \mathrm{H}_{8}+48 \mathrm{Fe}(\mathrm{OH})_{3} \rightarrow & 10 \mathrm{HCO}_{3}^{-}+48 \mathrm{Fe}^{2+} \\
+ & 28 \mathrm{H}_{2} \mathrm{O}+86 \mathrm{OH}^{-}
\end{aligned}
$$

The 1-methylnaphthalene-degrading enrichment was also cultivated with 1-, and 2-naphthoic acids (Fig. 3). Degradation of $315 \pm 57 \mu \mathrm{M}$ of 2-naphthoic acid within 97 days was coupled to production of $12.3 \mathrm{mM}$ of Fe(II) (Fig. 3a). The 1-methylnaphthalene-degrading enrichment consumed $160 \pm 43 \mu \mathrm{M}$ of 1-naphthoic acid within 34 days and produced $3.0 \pm 0.32 \mathrm{mM}$ of $\mathrm{Fe}$ (II) (Fig. 3b). According to the stoichiometric equation Eq. (3), consumption of $315 \mu \mathrm{M}$ of 2-naphthoic acid and $160 \mu \mathrm{M}$ of 1-naphthoic acid should be coupled to production of $15 \mathrm{mM}$ and $7.6 \mathrm{mM}$ of $\mathrm{Fe}(\mathrm{II})$, respectively. However, 2.8 or $4.5 \mathrm{mM}$ of $\mathrm{Fe}(\mathrm{II})$ were not recovered.
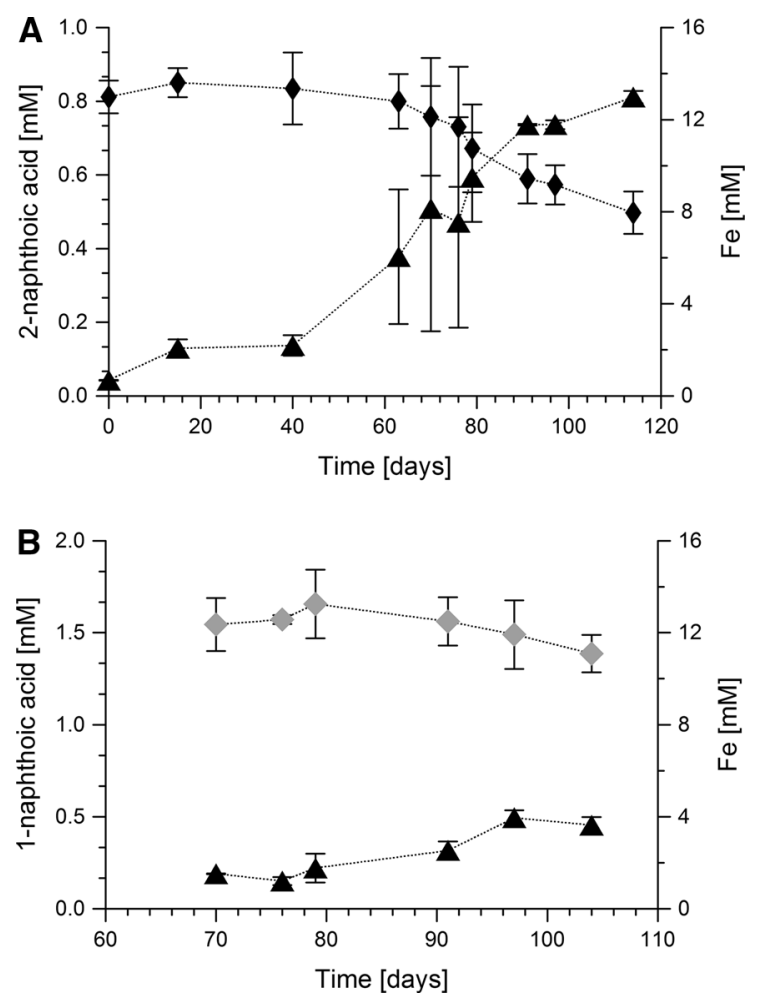

Fig. 3 Growth of the 1-methylnaphthalene degrading enrichment $1 \mathrm{MN}$ with 2-naphthoic acid (a) and 1-naphthoic acid (b). Error bars indicate standard deviations of two biological replicates. Filled triangles, Fe(II); black diamonds, 2-naphthoic acid; grey diamonds, 1-naphthioc acid

$$
\begin{aligned}
\mathrm{C}_{11} \mathrm{H}_{8} \mathrm{O}_{2}+48 \mathrm{Fe}(\mathrm{OH})_{3} \rightarrow & 11 \mathrm{HCO}_{3}^{-}+48 \mathrm{Fe}^{2+} \\
& +28 \mathrm{H}_{2} \mathrm{O}+85 \mathrm{OH}^{-}
\end{aligned}
$$

The experiments with 1-methylnaphthalene or naphthalene as carbon sources showed up to $300 \%$ more $\mathrm{Fe}(\mathrm{II})$ produced than expected indicating the presence of further electron sources in the culture medium. We added $0.7 \mathrm{mM} \mathrm{Na}_{2} \mathrm{~S}$ as a reducing agent which would account for the reduction of $5.6 \mathrm{mM} \mathrm{Fe}(\mathrm{III})$ if fully oxidized to $\mathrm{SO}_{4}{ }^{2-}$ (Eqs. 4, 5). $\mathrm{HS}^{-}$reacts spontaneously with $\mathrm{Fe}(\mathrm{III})$ producing ferrous iron and elemental sulfur (Eq. 4) (Poulton 2003; Hellige et al. 2012). The elemental sulfur could then be disproportionated by bacteria to sulfate and sulfide (Eq. 4) which again can be abiotically oxidized by $\mathrm{Fe}(\mathrm{OH})_{3}$ reduction (Thamdrup et al. 1993; Finster et al. 1998) (Eq. 5).

$$
\begin{array}{r}
3 \mathrm{HS}^{-}+2 \mathrm{Fe}(\mathrm{OH})_{3}+3 \mathrm{H}^{+} \\
\rightarrow 2 \mathrm{FeS}+\mathrm{S}^{0}+6 \mathrm{H}_{2} \mathrm{O}
\end{array}
$$

$4 \mathrm{~S}_{0}+4 \mathrm{H}_{2} \mathrm{O} \rightarrow \mathrm{SO}_{4}^{2-}+3 \mathrm{HS}^{-}+5 \mathrm{H}^{+}$

In order to prove that a potential sulfur cycle could be involved in iron reduction, we grew the enrichment without any organic electron donors and only with $0.7 \mathrm{mM} \mathrm{Na}_{2} \mathrm{~S}$ and $30 \mathrm{mM} \mathrm{Fe}(\mathrm{OH})_{3}$ as electron donor and acceptor, respectively. After 27 days of incubation about $1.2 \mathrm{mM} \mathrm{Fe}(\mathrm{II})$ and $0.3 \mathrm{mM}$ sulfate were produced (Fig. S1). Both values are much higher than expected from sulfur disproportionation alone indicating a complete oxidation of elemental sulfur to sulfate via an intermediate oxidation of sulfide to sulfur by iron reduction. Involvement of a sulfur cycle is also supported by the fact that enrichment culture $1 \mathrm{MN}$ was not able to grow in the same culture medium where $\mathrm{Na}_{2} \mathrm{~S}$ was replaced by $\mathrm{FeCl}_{2}$.

In a separate experiment, the amount of ATP was analyzed as a measure of biomass and microbial growth with 1-methylnaphthalene. ATP was chosen to monitor cell numbers due to high amounts of solid $\mathrm{Fe}(\mathrm{OH})_{3}$ prohibiting microscopic cell counting. Presence of two ATP peaks indicated different time points with especially high activity (Fig. 4). The first high ATP peak indicates high metabolic activity at the start of growth. The second ATP peak corresponds to the steepest increase in Fe(II) after 100 days of cultivation. These two points of high activity might be related 


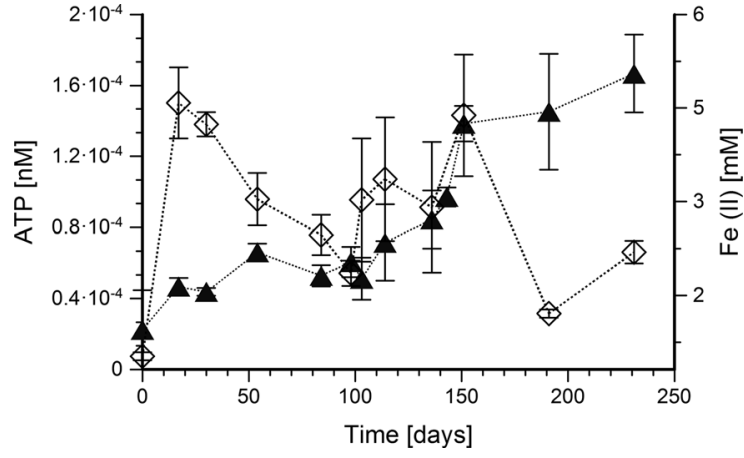

Fig. 4 ATP production by the 1-methylnaphthalene-degrading enrichment $1 \mathrm{MN}$. Error bars represent standard deviations of two biological replicates. Filled triangles, $\mathrm{Fe}$ (II) concentrations; open diamonds, ATP concentrations

to initial sulfur disproportionation and subsequent active growth on 1-methylnaphthalene.

Metabolites produced during growth with 1- and 2methylnaphthalene and naphthalene

When the culture was grown with 1-methylnaphthalene, 2-methylnaphthalene, or naphthalene, the following metabolites were detected in the culture medium: 1-naphthoic, 2-naphthoic, and 2-naphthoic acid, respectively (Fig. 5). The production of the metabolites was detected during growth, but was inconsistent over time (Fig. 5). The other putative acids from downstream degradation detected by GCMS are mentioned in Supplementary material, Fig. S2.

Analysis of the microbial community composition of enrichment culture $1 \mathrm{MN}$

To identify the microorganisms involved in naphthalene degradation by culture 1MN, T-RFLP and sequence analyses of the 16S rRNA genes were performed. The electropherogram of $16 \mathrm{~S}$ rRNA gene amplicons of the DNA extracted from cells grown with 1-methylnaphthalene showed three dominant TRF peaks of 149, 160, and $215 \mathrm{bp}$ (Fig. 6). T-RFLP analyses of cultures incubated with 2-methylnaphthalene and naphthalene did not show significant changes in microbial composition indicating that the same microorganisms were responsible for the degradation (Supplementary data, Fig. S3). Only the abundance of the $160 \mathrm{bp}$ peak decreased during later stages of degradation with
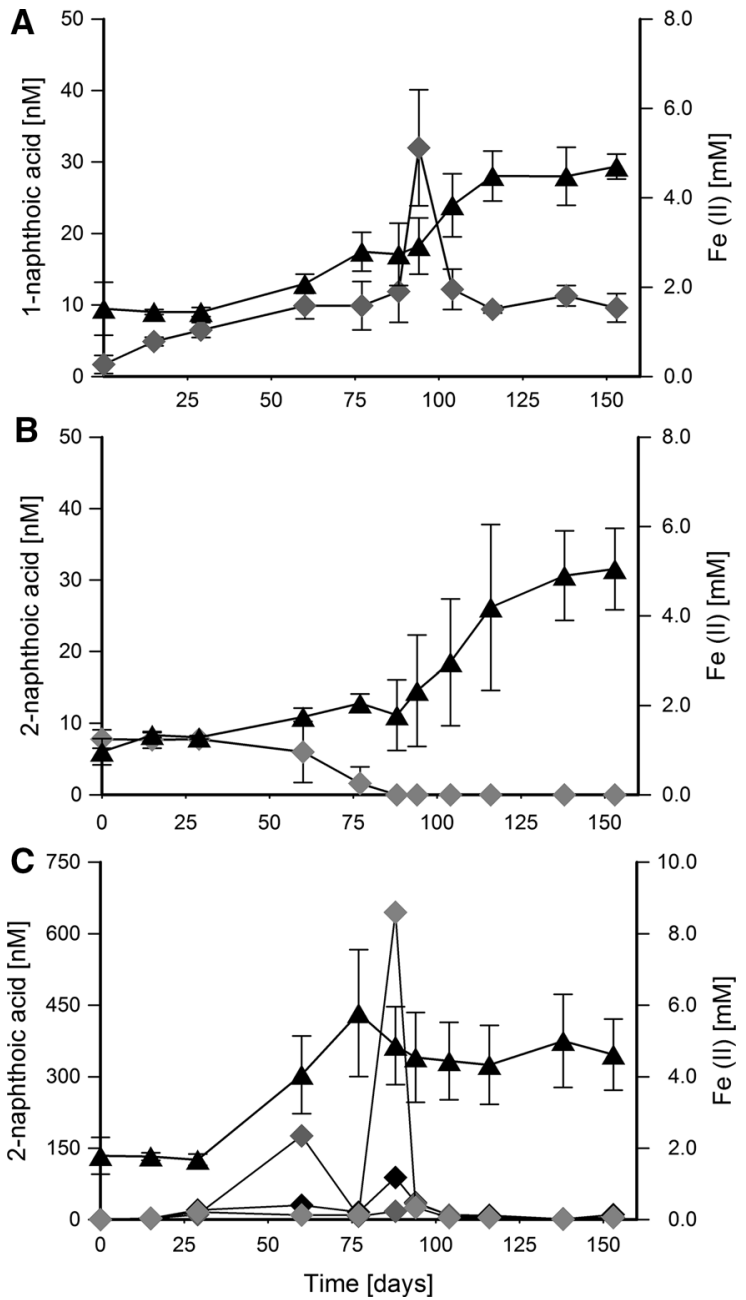

Fig. 5 Production of $\mathrm{Fe}(\mathrm{II})$ and naphthoic acids by the 1-methylnaphthalene-degrading enrichment $1 \mathrm{MN}$ during growth with a 1-methylnaphthalene, b 2-methylnaphthalene, and $\mathbf{c}$ naphthalene. Error bars represent standard deviations of three biological replicates. In graph (c) measurements for naphthoic acids are not averaged because the production of the naphthoic acids strongly differed between the replicates. Filled triangles, Fe(II) concentrations; diamonds, naphthoic acid concentrations; different colors of diamonds in graph (c) represent individual biological replicates

naphthalene and 2-methylnaphthalene (Supplementary data, Fig. S3). However, when growing the culture in the absence of an organic carbon source only with the reducing agent $0.7 \mathrm{mM} \mathrm{Na} 2 \mathrm{~S}$ and $30 \mathrm{mM} \mathrm{Fe}(\mathrm{OH})_{3}$ as electron acceptor, the abundances changed drastically. TRFs 149 and 215 were not detectable anymore, whereas TRF 160 was highly enriched to more than $90 \%$ relative abundance in two replicate cultures (Fig. S1b). 


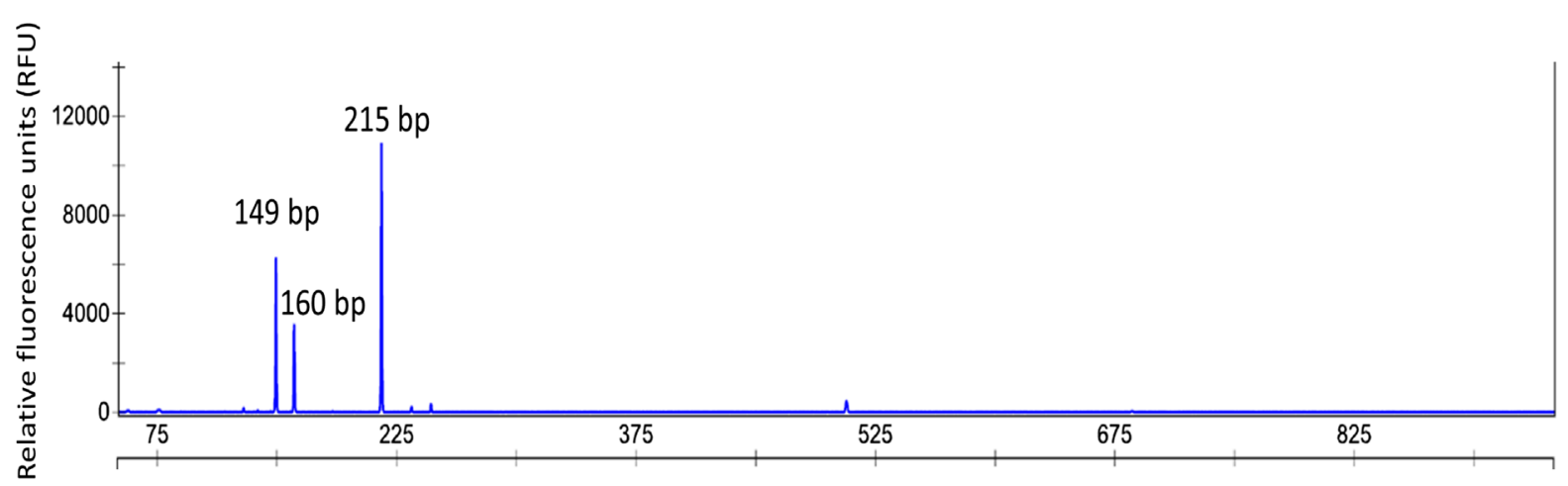

Fig. 6 Electropherogram of a T-RFLP analysis of the 1-methylnaphthalene-degrading enrichment $1 \mathrm{MN}$ incubated with 1-methylnaphthalene as sole carbon and electron source. Numbers above the T-RF peaks give their length in base pairs

To correlate the results of the T-RFLP analysis with the microbial phylogenetic affiliation, we performed pyrosequencing of 16S rRNA gene sequences with subsequent creation of contigs and in silico restriction. In general, 10 contigs were generated, four of them representing $90 \%$ of the community (Supplementary data, Table S1). The contigs corresponding to TRF peaks of 149 (contigs 3 and 4) and 215 bp (contig 1) were almost identical: contig 1 was similar to contigs 3 and 4 by $98.7 \%$ while contigs 3 and 4 were similar to each other by $98.4 \%$ (according to sequence identity matrix created in Bioedit). These three contigs represented together $62 \%$ of the community (Supplementary data, Table S1). According to the RDP Classifier, the contigs corresponding to TRF peaks 149 and 215 bp belong to Clostridia (95\% classification reliability), Thermoanaerobacterales (84\% classification reliability), Thermoanaerobacteraceae ( $84 \%$ classification reliability) and are distantly related $(92 \%$ identical) to Clostridial gene clones from microorganisms enriched from oilfields under mesophilic and thermophilic conditions (Cheng et al. 2014) (Fig. 7). The sequence similarity of the $16 \mathrm{~S}$ rRNA genes indicates that the contigs are from different strains of the same species. The other abundant contig (29\% from all reads) corresponded to the $160 \mathrm{bp}$ TRF peak and based on RDP classification belonged to the Deltaproteobacteria, Desulfobacterales (94\% classification reliability), Desulfobulbaceae (65\% classification reliability) and has $99 \%$ similarity to clones from an enrichment study where acetate was amended into sediment columns with sulfate as electron acceptor (Handley et al. 2013) (Fig. 7).
SIP-experiment with ${ }^{13} \mathrm{C}_{10^{-}}$-naphthalene and ${ }^{12} \mathrm{C}_{10^{-}}$ naphthalene as a control was performed to investigate whether Clostridia or Desulfobacterales play an active role in naphthalene degradation. DNA was harvested after 72 and 97 days of incubation resulting in early and late labelling. The time difference between the sampling was caused by different growth rates in the biological replicates (Fig. 2b). After density centrifugation, the distribution of bacterial 16S rRNA gene copies in ${ }^{12} \mathrm{C}$ - and ${ }^{13} \mathrm{C}$-gradients was investigated in six fractions which retrieved approximately $97 \%$ of the loaded DNA (Fig. 8). T-RFLP analysis was performed on the six gradient fractions with most of the DNA detected. In both samples (late and early labeling, Fig. 8a, c), the "heavy" fractions at 1.701 and $1.703 \mathrm{~g} \mathrm{ml}^{-1}$, respectively, were dominated by the 149 and 215 bp T-RF peaks of Clostridia and were shifted from the "light gradients" with the highest Clostridia peak by $0.008 \mathrm{~g} \mathrm{ml}^{-1}$ (corresponding to $20 \%$ label incorporation). According to (Lueders 2017), 20\% labeling is regarded as the detection limit for SIP. In contrast, the $160 \mathrm{bp}$ T-RF peak of the Desulfobulbacterales was dominant at 1.696 and $1.694 \mathrm{~g} \mathrm{ml}^{-1}$ in the late and early labeling experiments, respectively (Fig. 8a, c). T-RF peaks of Clostridia and Desulfobulbacterales did not show any shifts between the collected fractions in control experiments where ${ }^{12} \mathrm{C}$-naphthalene was used as a carbon source (Fig. 8b, d). Therefore, the incorporation of ${ }^{13} \mathrm{C}$-naphthalene is reflected in the DNA of Clostridia, suggesting that these are the key-degraders of naphthalene.

To verify the results from the SIP experiment, the metagenome of culture $1 \mathrm{MN}$ grown on ${ }^{13} \mathrm{C}$-labeled 


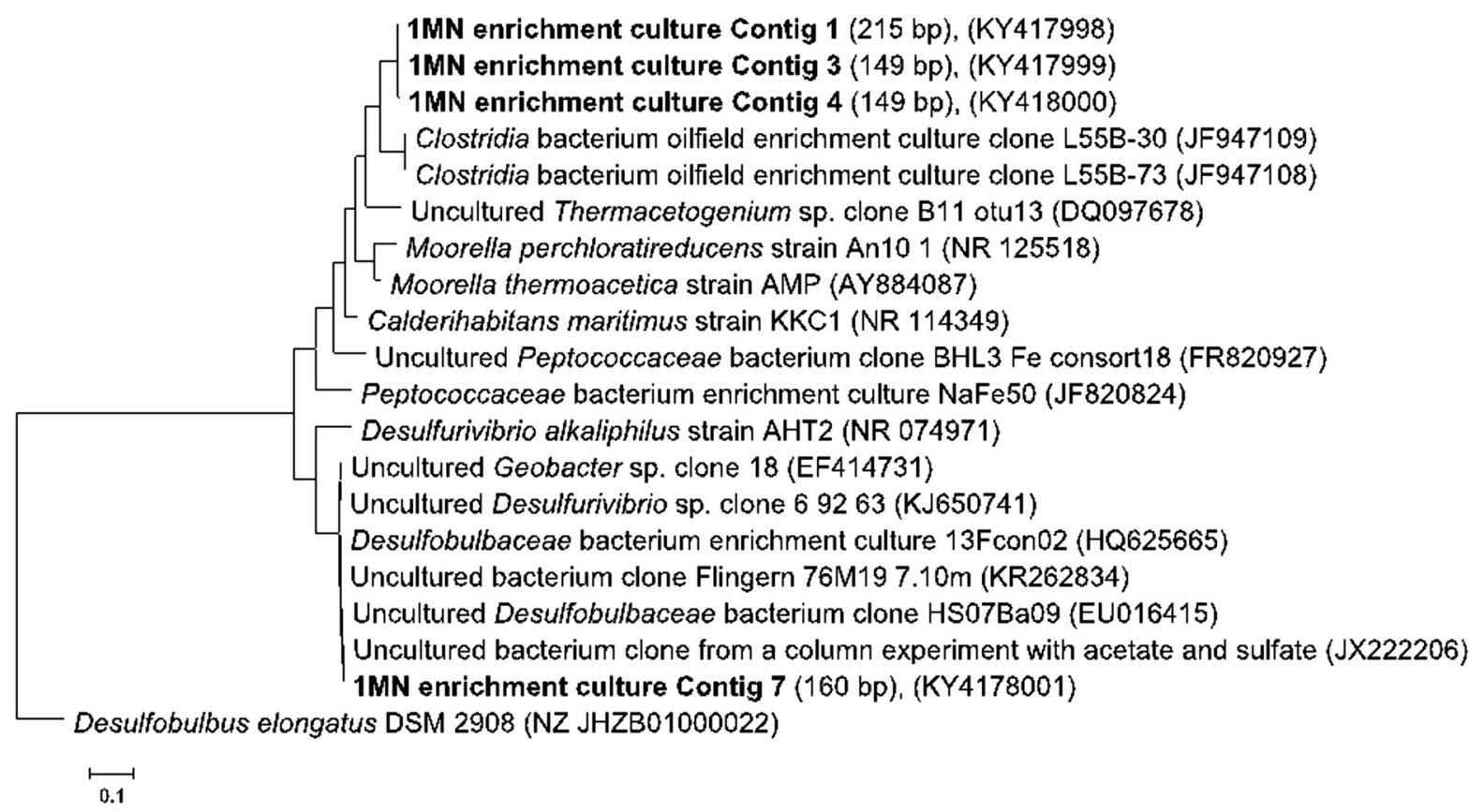

Fig. 7 Phylogenetic tree created by maximum likelihood positioning of $16 \mathrm{~S}$ rRNA gene sequences obtained from the 1-methylnaphthalene-degrading enrichment culture $1 \mathrm{MN}$. The tree was rooted on Desulfobulbus elongatus DSM 2908 as

naphthalene from day 97 underwent metagenomic sequencing. Raw sequencing reads assembled into 171 scaffolds, longer than 1000 base pairs. To identify the organism involved in naphthalene, 1-, and 2-methylnaphthalene degradation, we screened for fumarate addition and naphthalene carboxylase genes previously reported to be involved in PAHs degradation (Kleemann and Meckenstock, 2011; Mouttaki et al. 2012). Only two putative fumarate addition genes encoding proteins with low identity (31 and 39.5\%) to the naphthyl-2-methylsuccinate synthase (nmsA) gene of the sulfate-reducing enrichment culture N47 were identified in the entire metagenomic dataset (Figure S4, Table S2). These genes were located on 131- and 127-kb long scaffolds, respectively. The scaffolds encoded for 121 and 128 other proteins, respectively, 106 and 105 of which were classified as Clostridia (103/101). Four genes on the scaffolds were annotated as ribosomal proteins from members of the Clostridia. To identify genes encoding for naphthalene carboxylases, the metagenome was screened by blastp using sequences of the previously described putative naphthalene carboxylation gene cluster of the naphthalene degrading culture N47 (Bergmann et al. outgroup. Sequences retrieved from the enrichment culture are depicted in bold. The bar indicates $10 \%$ estimated sequence divergence

2011). A whole gene cluster was detected on a $51-\mathrm{kb}$ long scaffold coding for 47 proteins of which 39 have blast hits against the Uniref100 database. 21 of the proteins were annotated to proteins of Clostridia. Three of the proteins have blast hits against four putative naphthalene carboxylases in N47 with gene identities between 32 and 51\% (Figure S5, Table S3, Table S4). The presence of the putative nmsA genes and the putative naphthalene carboxylase gene cluster on scaffolds classified as Clostridia further supports that the Thermoanaerobacteraceae are the key-degraders of 1-methylnaphthalene in the enrichment culture.

\section{Discussion}

The present study describes a culture which was enriched with 1-methylnaphthalene as electron donor and ferrihydrite as electron acceptor. Despite our efforts of performing serial dilutions to extinction we could not obtain a pure culture, so far. 

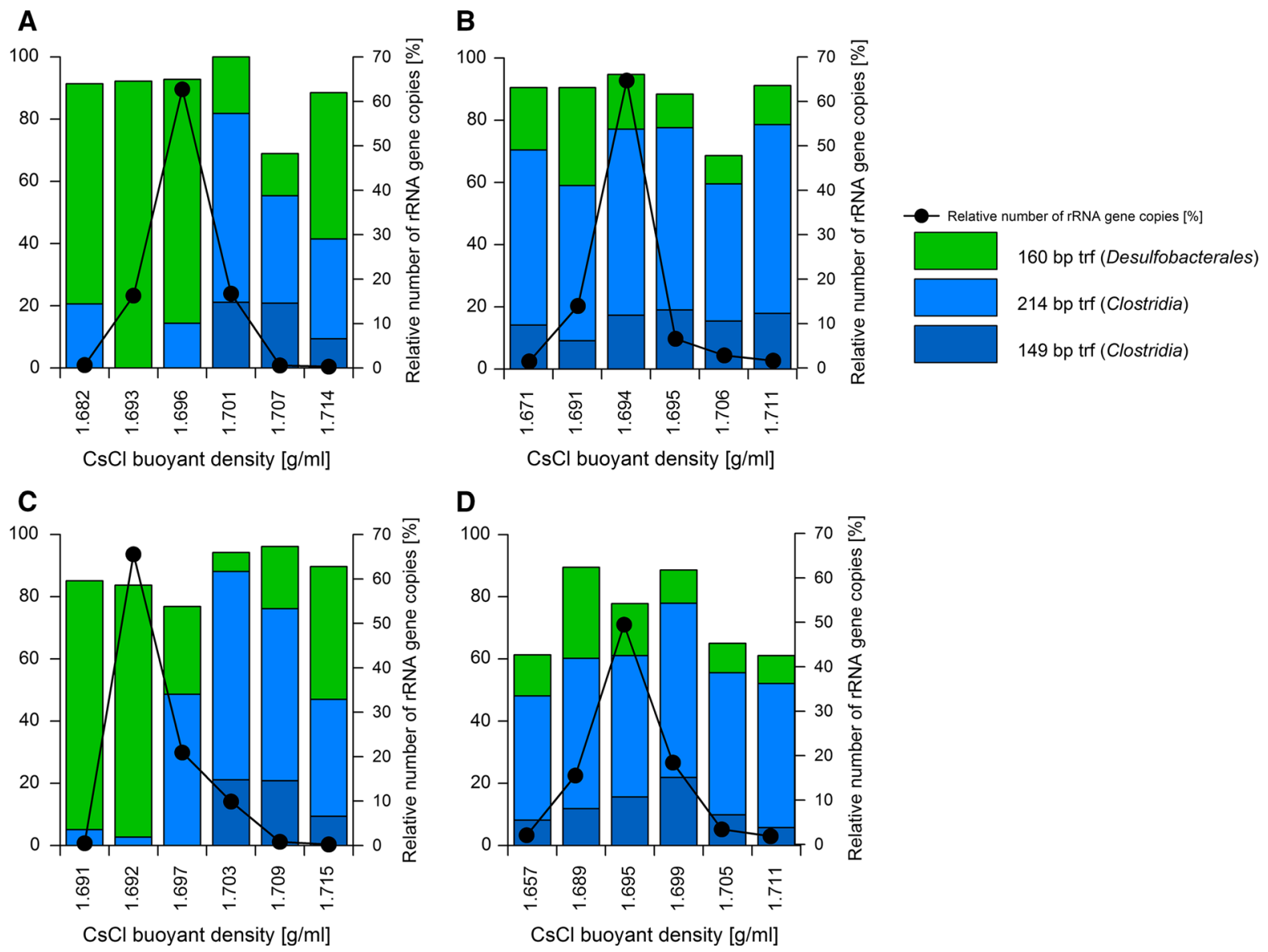

Fig. 8 Relative T-RF abundances and relative number of rRNA gene copies distribution in comparative $\mathrm{CsCl}$ density-gradient centrifugations of DNA extracted from the 1-methylnaphthalene-degrading, iron-reducing enrichment $1 \mathrm{MN}$ incubated with either ${ }^{13} \mathrm{C}_{10}$-naphthalene (a, c) or ${ }^{12} \mathrm{C}_{10}$-naphthalene (b, d) at $72 \mathrm{~h}$ of cultivation $(\mathbf{a}, \mathbf{b})$ and 97 days of cultivation $(\mathbf{c}, \mathbf{d})$.

Phylogenetic affiliation

T-RFLP analysis, pyrosequencing data and phylogenetic analysis showed that the enrichment culture consisted mainly of two types of microorganisms belonging to the Thermoanaerobacteraceae (approximately $60 \%$ of community) and the Desulfobulbaceae (approximately 29\% of community). Stable isotope probing revealed that the biodegradation of naphthalene was carried out by members of the Clostridia. This was also supported by the detection of a putative naphthalene carboxylation gene cluster on a scaffold classified as Clostridia (Figure S5, Table S3, Table S4). Clostridia species in this study have $85 \%$ classification reliability to the order
Distribution of bacterial 16S rRNA genes within density gradient fractions was quantified by real-time qPCR; relative number of rRNA gene copies distribution was calculated for all twelve collected fractions, but only presented here for the fractions for which T-RFLP analysis was performed

Thermoanaerobacteriales and the closest relatives (92\% similarity) in the gene bank are clones from an enrichment with oily sludge under mesophilic and thermophilic conditions (Cheng et al. 2014). Moreover, there is only $88 \%$ similarity to members of the Peptococcaceae identified in an enrichment which also degrades naphthalene and 1-, and 2-methylnaphthalene under iron-reducing conditions (Kleemann and Meckenstock 2011). The closest described cultivated representatives are a hydrogenogenic, carboxydotrophic, thermophilic marine bacterium Calderihabitans maritimus $\mathrm{KKC1}(\mathrm{T})$ (Yoneda et al. 2013) (88\% sequence identity), Moorella perchloratireducens An10 (87\% sequence identity) (Pierce et al. 2008), and Moorella thermoacetica AMP (86\% 
sequence identity) (Balk et al. 2008). C. maritimus $\mathrm{KKC1}(\mathrm{T})$ and Moorella species are spore-forming thermophilic bacteria, which can use thiosulfate, fumarate, $\mathrm{Fe}(\mathrm{III})$, nitrate or perchlorate (Pierce et al. 2008) as electron acceptors and produce acetate via the Wood-Ljundal pathway (Tindall et al. 2010). $C$. maritimus $\mathrm{KKC1}(\mathrm{T})$, in particular, is able to produce $\mathrm{H}_{2} \mathrm{~S}$ from $\mathrm{CO}$ oxidation coupled to sulfite or thiosulfate reduction (Tindall et al. 2010). The very low similarity on 16S rRNA sequence level of the clostridial member in our enrichment $1 \mathrm{MN}$ suggests a new species if not a novel genus. Nevertheless, this awaits isolation and strain description.

The closest relatives of the Desulfobulbaceae in the gene bank (99\% sequence identity) were clones isolated from an aquifer sediment column amended with acetate under sulfate-reducing conditions (Handley et al. 2013), from an industrial site contaminated with petroleum hydrocarbons (Zhang et al. 2012b), from an uranium-contaminated groundwater where acetate was used for bioremediation (Elifantz et al. 2010; Holmes et al. 2007), and recently discovered cable bacteria in groundwater aquifers ( $98 \%$ sequence identity) (Müller et al. 2016). The closest described relative (88\% sequence identity) is Desulfurivibrio alkaliphilus AHT2 (Melton et al. 2016). Also for the Desulfobulbaceae, the phylogenetic distance of more than 5\% from their closest described neighbors suggests that these two organisms might represent novel genera (Tindall et al. 2010).

The role of gram-positive microorganisms in the degradation of aromatic hydrocarbons

Several studies have demonstrated that gram-positive bacteria play an important role in the biodegradation of aromatic pollutants such as biphenyl by Desulfotomaculum (Selesi and Meckenstock 2009), benzene by Peptococcaceae (Kunapuli et al. 2007), and Pelotomaculum (Abu Laban et al. 2009), or naphthalene, 1- and 2-methylnaphthalene by Peptococcaceae (Kleemann and Meckenstock 2011). Only few pure gram-positive strains belonging to the genus Desulfitobacterium (Villemur et al. 2006; Kunapuli et al. 2010), Desulfosporosinus (Robertson et al. 2001; Liu et al. 2004) and Desulfotomaculum (Plugge et al. 2002; Morasch et al. 2004) capable of degrading monoaromatic hydrocarbons under iron- or sulfatereducing conditions have been described. Although an enrichment culture dominated by one microorganism belonging to Peptococcaceae capable of naphthalene degradation coupled to $\mathrm{Fe}(\mathrm{OH})_{3}$ reduction has been reported (Kleemann and Meckenstock 2011), no pure anaerobic strains of gram-positive PAH-degrading bacteria have been described so far. The difficulty in isolating such strains indicates the importance of the co-cultured members reported here. Recently, Desulfobacterales have been shown to play an important role in hydrogen consumption (Burow et al. 2014) in the environment. Similarly, the Clostridia in our enrichment might produce hydrogen during consumption of naphthalene which in turn would be consumed by Desulfobacterales pulling the reaction towards complete naphthalene oxidation to $\mathrm{CO}_{2}$. However, also other types of interaction such as a cryptic sulfur cycle are possible.

The current enrichment culture is the second culture reported to degrade naphthalene, 1-methylnaphthalene and 2-methylnaphthalene under iron-reducing conditions and the first to degrade PAHs in a community consisting of Thermoanaerobacteraceae and Desulfobulbaceae with $\mathrm{Fe}(\mathrm{OH})_{3}$ as an electron acceptor. It is not clear, why there was no sulfate reduction observed as Desulfobulbaceae are also expected to reduce sulfate. This example demonstrates that $\mathrm{Fe}(\mathrm{III})$-dependent biodegradation of PAHs might play an important role in iron-rich, anoxic habitats. Thermoanaerobacteraceae are prominent community members in oil reservoirs (Canganella and Wiegel 2014; Cheng et al. 2014) but to our knowledge were not shown to degrade hydrocarbons, so far. Our culture reveals that the Thermoanaerobacteraceae can be involved in hydrocarbon degradation but the exact mode of their electron accepting process remains open.

How Thermoanaerobacteraceae can interact with Desulfobulbaceae?

The current study does not provide direct evidence on relationship of Clostridia and Desulfobulbaceae in the 1-methylnaphthalene degrading enrichment, but gives some suggestions on their possible interactions. One option could be a synthrophy. Based on SIP analysis, Kunapuli and colleagues (Kunapuli et al. 2007) proposed that under iron-reducing conditions grampositive members of culture BF metabolize benzene and produce $\mathrm{H}_{2}$, while gram-negative 
Desulfobulbaceae consume $\mathrm{H}_{2}$ and transfer electrons to $\mathrm{Fe}(\mathrm{OH})_{3}$. To our knowledge, no degradation of naphthalene by synthrophic communities rather than methanogenic has been described so far (Gieg et al. 2014). On another side, our experiments where the $1 \mathrm{MN}$ enrichment culture produced sulfate and ferrous iron in the absence of any carbon substrate (and this was coupled to increased abundance of Desulfobulbaceae) might suggest that Desulfobulbaceae can grow independently from Clostridia. Active degradation of naphthalene (and AQDS reduction) always started after a lag phase where up to $2 \mathrm{mM}$ of Fe(II) has been produced. We suggest that Desulfobulbaceae oxidize or disproportionate elemental sulfur coupled to iron reduction. In the absence of organic carbon sources, the Desulfobulbaceae are probably capable of $\mathrm{CO}_{2}$ fixation to build up biomass. As soon as their biomass is high enough, Clostridia can start degrading 1-methylnaphthalene and excrete electrons in the form of easily degradable substrates/metabolites which can be further oxidized by Desulfobulbaceae and coupled to rapid Fe(II) reduction. Thus, 3,4-dihydroxybutanoic acid has been detected in culture supernatants (Supplementary material, Fig. S1C) and could be one of the metabolites excreted by Clostridia and consumed by Desulfobulbaceae. Follow-up metagenomics analysis will give more detailed insights into functional capabilities of Clostridia and Desulfobulbaceae from our enrichment culture.

\section{Degradation of 1-methylnaphthalene}

Several studies exist on anaerobic degradation of naphthalene or 2-methylnaphthalene under sulfatereducing conditions in sediments (Coates et al. 1996; Anderson and Lovley 1999), enriched microcosms (Bedessem et al. 1997; Sullivan et al. 2001; Zhang et al. 2003) as well as in sediment-free liquid cultures (Annweiler et al. 2000; Meckenstock et al. 2000; Musat et al. 2009; Kümmel et al. 2015). However, the described sulfate-reducing cultures are able to degrade only naphthalene and 2-methylnaphthalene but not 1-methylnaphthalene. In fact, there has been only one study so far that reported on a culture oxidizing 1-methylnaphthalene coupled to iron reduction in sediment-free highly enriched culture (Kleemann and Meckenstock 2011).

In sulfate-reducing microorganisms, 2-naphthoic acid is a central metabolite produced either via carboxylation of naphthalene (Zhang and Young 1997, Meckenstock et al. 2000) or via addition of fumarate to 2-methylnaphthalene and subsequent betaoxidation (Meckenstock et al. 2016) (Fig. 1b, c). Detection of 1-naphthoic acid as a metabolite during the 1-methylnaphthalene biodegradation in our study indicates that 1-naphthoic acid can be another central metabolite in anaerobic degradation of naphthalenes besides 2-naphthoic acid (Fig. 1a). Most likely, it is produced via fumarate addition to naphthyl-1-methylsuccinic acid, similar to the degradation of 2-methylnaphthalene. This was supported by detection of putative fumurate addition genes encoding proteins analogues to naphthyl-2-methylsuccinate synthase (NmsA). The low identity of corresponding genes (Fig. S4) to NmsA from sulfate-reducing enrichment N47 might indicated a new clade of fumarate addition genes in the Thermoanaerobacter-related microorganisms. Further degradation steps in the downstream metabolism of 1-naphthoic acid including ring reduction and cleavage as well as beta-oxidation of dicarboxylic acids are probably also similar to the degradation of 2-naphthoic acid. However, the specific metabolites must be different up to the step where ring I of the 1-naphthoic acid is cleaved by a hydrolase reaction and the first acetyl-CoA unit has been removed by beta-oxidation leading to a cyclohexane ring with one acetyl and one carboxylic acid side chain.

Acknowledgements We thank Dr. Tillmann Lueders for introduction to stable isotope probing and valuable advice, and Katrin Hörmann and Gabriele Barthel for technical support in pyrosequencing. This research was funded by the Helmholtz Zentrum München. R.U.M. acknowledges funding from the ERC 562 advanced grant EcOILogy (No. 666952).

Open Access This article is distributed under the terms of the Creative Commons Attribution 4.0 International License (http:// creativecommons.org/licenses/by/4.0/), which permits unrestricted use, distribution, and reproduction in any medium, provided you give appropriate credit to the original author(s) and the source, provide a link to the Creative Commons license, and indicate if changes were made.

\section{References}

Abu Laban N, Selesi D, Jobelius C, Meckenstock RU (2009) Anaerobic benzene degradation by gram-positive sulfatereducing bacteria. FEMS Microbiol Ecol 68:300-311 
Anderson RT, Lovley DR (1999) Naphthalene and benzene degradation under $\mathrm{Fe}(\mathrm{III})$-reducing conditions in petroleum-contaminated aquifers. Bioremediat J 3:121-135

Annweiler E, Materna A, Safinowski M, Kappler A, Richnow HH, Michaelis W, Meckenstock RU (2000) Anaerobic degradation of 2-methylnaphthalene by a sulfate-reducing enrichment culture. Appl Environ Microbiol 66:5329-5333

Balk M, van Gelder T, Weelink SA, Stams AJA (2008) (Per)chlorate reduction by the thermophilic bacterium Moorella perchloratireducens sp nov., isolated from underground gas storage. Appl Environ Microbiol 74:403-409

Bedessem ME, SwobodaColberg NG, Colberg PJS (1997) Naphthalene mineralization coupled to sulfate reduction in aquifer-derived enrichments. FEMS Microbiol Lett 152:213-218

Bergmann FD, Selesi D, Meckenstock RU (2011) Identification of new enzymes potentially involved in anaerobic naphthalene degradation by the sulfate-reducing enrichment culture N47. Arch Microbiol 193:241-250

Braunschweig J, Bosch J, Heister K, Kuebeck C, Meckenstock RU (2012) Reevaluation of colorimetric iron determination methods commonly used in geomicrobiology. J Mirobiol Methods 89:41-48

Buchfink B, Xie C, Huson DH (2015) Fast and sensitive protein alignment using DIAMOND. Nat Methods 12:59-60

Burow LC, Woebken D, Marshall IPG et al (2014) Identification of Desulfobacterales as primary hydrogenotrophs in a complex microbial mat community. Geobiology 12:221-230

Canganella F, Wiegel J (2014) Anaerobic thermophiles. Life 4:77-104

Cheng L, Shi SB, Li Q, Chen JF, Zhang H, Lu YH (2014) Progressive degradation of crude oil n-alkanes coupled to methane production under mesophilic and thermophilic conditions. PLoS ONE 9(11):e113253

Christensen N, Batstone DJ, He Z, Angelidaki I, Schmidt J (2004) Removal of polycyclic aromatic hydrocarbons (PAHs) from sewage sludge by anaerobic degradation. Water Sci Technol 50:237-244

Cline JD (1969) Spectrophotometric determination of hydrogen sulfide in natural waters. Limnol Oceanogr 14(3):454-458

Coates JD, Anderson RT, Lovley DR (1996) Oxidation of polycyclic aromatic hydrocarbons under sulfate-reducing conditions. Appl Environ Microbiol 62:1099-1101

Coates JD, Bhupathiraju VK, Achenbach LA, McInerney MJ, Lovley DR (2001) Geobacter hydrogenophilus, Geobacter chapellei and Geobacter grbiciae, three new, strictly anaerobic, dissimilatory Fe(III)-reducers. Int J Syst Evol Microbiol 51:581-588

Elifantz H, N'Guessan LA, Mouser PJ et al (2010) Expression of acetate permease-like (apl) genes in subsurface communities of Geobacter species under fluctuating acetate concentrations. FEMS Microbiol Ecol 73:441-449

Finster K, Liesack W, Thamdrup B (1998) Elemental sulfur and thiosulfate disproportionation by Desulfocapsa sulfoexigens sp. nov., a new anaerobic bacterium isolated from marine surface sediment. Appl Environ Microbiol 64:119-125
Folwell BD, McGenity TJ, Price A, Johnson RJ, Whitby C (2016) Exploring the capacity for anaerobic biodegradation of polycyclic aromatic hydrocarbons and naphthenic acids by microbes from oil-sands-process-affected waters. Intern Biodeter Biodegrad 108:214-221

Galushko A, Minz D, Schink B, Widdel F (1999) Anaerobic degradation of naphthalene by a pure culture of a novel type of marine sulphate-reducing bacterium. Environ Microbiol 1:415-420

Galushko A, Kiesele-Lang U, Kappler A (2003) Degradation of 2-methylnaphthalene by a sulfate-reducing enrichment culture of mesophilic freshwater bacteria. Polycycl Aromat Compd 23:207-218

Genthner BS, Townsend G, Lantz S, Mueller J (1997) Persistence of polycyclic aromatic hydrocarbon components of creosote under anaerobic enrichment conditions. Arch Environ Contam Toxicol 32:99-105

Gieg LM, Fowler SJ, Berdugo-Clavijo C (2014) Syntrophic biodegradation of hydrocarbon contaminants. Curr Opin Biotechnol 27:21-29

Hall BG (2013) Building phylogenetic trees from molecular data with MEGA. Mol Biol Evol 30:1229-1235

Hammes F, Goldschmidt F, Vital M, Wang YY, Egli T (2010) Measurement and interpretation of microbial adenosine triphosphate (ATP) in aquatic environments. Water Res 44:3915-3923

Handley KM, VerBerkmoes NC, Steefel CI et al (2013) Biostimulation induces syntrophic interactions that impact $\mathrm{C}, \mathrm{S}$ and $\mathrm{N}$ cycling in a sediment microbial community. ISME $\mathrm{J}$ 7:800-816

Hellige K, Pollok K, Larese-Casanova P, Behrends T, Peiffer S (2012) Pathways of ferrous iron mineral formation upon sulfidation of lepidocrocite surfaces. Geochim Cosmochim Acta 81:69-81

Holmes DE, O'Neil RA, Vrionis HA et al (2007) Subsurface clade of Geobacteraceae that predominates in a diversity of $\mathrm{Fe}(\mathrm{III})$-reducing subsurface environments. ISME J 1:663-677

Hyatt D, Chen G-L, LoCascio PF, Land ML, Larimer FW, Hauser LJ (2010) Prodigal: prokaryotic gene recognition and translation initiation site identification. BMC Bioinform 11:119

Junier P, Junier T, Witzel KP (2008) TRiFLe, a program for in silico terminal restriction fragment length polymorphism analysis with user-defined sequence sets. Appl Environ Microbiol 74:6452-6456

Kleemann R, Meckenstock RU (2011) Anaerobic naphthalene degradation by gram-positive, iron-reducing bacteria. FEMS Microbiol Ecol 78:488-496

Kümmel S, Herbst F-A, Bahr A et al (2015) Anaerobic naphthalene degradation by sulfate-reducing Desulfobacteraceae from various anoxic aquifers. FEMS Microbiol Ecol 91:fiv006

Kunapuli U, Lueders T, Meckenstock RU (2007) The use of stable isotope probing to identify key iron-reducing microorganisms involved in anaerobic benzene degradation. ISME J 1:643-653

Kunapuli U, Jahn MK, Lueders T, Geyer R, Heipieper HJ, Meckenstock RU (2010) Desulfitobacterium aromaticivorans sp nov and Geobacter toluenoxydans sp nov., ironreducing bacteria capable of anaerobic degradation of 
monoaromatic hydrocarbons. Int J Syst Evol Microbiol 60:686-695

Lane D (1991) 16S/23S rRNA sequencing nucleic acid techniques in bacterial systematics. Wiley, New York

Langmead B, Salzberg SL (2012) Fast gapped-read alignment with Bowtie 2. Nat Methods 9:357-359

Linstrom PJ and Mallard W (2001) NIST Chemistry webbook; NIST standard reference database No. 69

Liu A, Garcia-Dominguez E, Rhine ED, Young LY (2004) A novel arsenate respiring isolate that can utilize aromatic substrates. FEMS Microbiol Ecol 48:323-332

Lovley DR, Phillips EJ (1988) Novel mode of microbial energy metabolism: organic carbon oxidation coupled to dissimilatory reduction of iron or manganese. Appl Environ Microb 54:1472-1480

Lovley DR, Giovannoni SJ, White DC, Champine JE, Phillips EJ, Gorby YA, Goodwin S (1993) Geobacter metallireducens gen. nov. sp. nov., a microorganism capable of coupling the complete oxidation of organic compounds to the reduction of iron and other metals. Arch Microbiol 159:336-344

Lueders T (2010) Stable isotope probing of hydrocarbon-degraders. In: Timmis K (ed) Handbook of hydrocarbon and lipid microbiology, vol 5. Springer, Berlin, pp 4011-4026

Lueders T (2017) DNA-and RNA-based stable isotope probing of hydrocarbon degraders. Hydrocarbon and lipid microbiology protocols: genetic, genomic and system analyses of communities. pp 181-197

Lueders T, Manefield M, Friedrich MW (2004) Enhanced sensitivity of DNA- and rRNA-based stable isotope probing by fractionation and quantitative analysis of isopycnic centrifugation gradients. Environ Microbiol 6:73-78

Lueders T, Kindler R, Miltner A, Friedrich MW, Kaestner M (2006) Identification of bacterial micropredators distinctively active in a soil microbial food web. Appl Environ Microbiol 72:5342-5348

Mahajan MC, Phale PS, Vaidyanathan CS (1994) Evidence for the involvement of multiple pathways in the biodegradation of 1-and 2-methylnaphthalene by Pseudomonas putida CSV86. Arch Microbiol 161:425-433

Meckenstock RU, Mouttaki H (2011) Anaerobic degradation of non-substituted aromatic hydrocarbons. Curr Opin Biotechnol 22:406-414

Meckenstock RU, Annweiler E, Michaelis W, Richnow HH, Schink B (2000) Anaerobic naphthalene degradation by a sulfate-reducing enrichment culture. Appl Environ Microbiol 66:2743-2747

Meckenstock RU, Elsner M, Griebler C et al (2015) Biodegradation: updating the concepts of control for microbial cleanup in contaminated aquifers. Environ Sci Technol 49:7073-7081

Meckenstock RU, Boll M, Mouttaki H et al (2016) Anaerobic degradation of benzene and polycyclic aromatic hydrocarbons. J Mol Microbiol Biotechnol 26:92-118

Melton ED, Sorokin DY, Overmars L et al (2016) Complete genome sequence of Desulfurivibrio alkaliphilus strain AHT2 T, a haloalkaliphilic sulfidogen from Egyptian hypersaline alkaline lakes. Stand Genomic Sci 11:67

Morasch B, Annweiler E, Warthmann RJ, Meckenstock RU (2001) The use of a solid adsorber resin for enrichment of bacteria with toxic substrates and to identify metabolites: degradation of naphthalene, o-, and m-xylene by sulfatereducing bacteria. J Microbiol Methods 44:183-191

Morasch B, Schink B, Tebbe CC, Meckenstock RU (2004) Degradation of o-xylene and m-xylene by a novel sulfatereducer belonging to the genus Desulfotomaculum. Arch Microbiol 181:407-417

Mouttaki H, Johannes J, Meckenstock RU (2012) Identification of naphthalene carboxylase as a prototype for the anaerobic activation of non-substituted aromatic hydrocarbons. Environ Microbiol 14:2770-2774

Mueller-Spitz S, Crawford K (2014) Silver nanoparticle inhibition of polycyclic aromatic hydrocarbons degradation by Mycobacterium species RJGII-135. Lett Appl Microbiol 58:330-337

Müller H, Bosch J, Griebler C, Damgaard LR, Nielsen LP, Lueders T, Meckenstock RU (2016) Long-distance electron transfer by cable bacteria in aquifer sediments. ISME J 10:2010-2019

Musat F, Galushko A, Jacob J et al (2009) Anaerobic degradation of naphthalene and 2-methylnaphthalene by strains of marine sulfate-reducing bacteria. Environ Microbiol 11:209-219

Nevin KP, Lovley DR (2002) Mechanisms for accessing insoluble $\mathrm{Fe}$ (III) oxide during dissimilatory $\mathrm{Fe}(\mathrm{III})$ reduction by Geothrix fermentans. Appl Environ Microbiol 68:2294-2299

Nurk S, Meleshko D, Korobeynikov A, Pevzner PA (2017) metaSPAdes: a new versatile metagenomic assembler. Genome Res 27:824-834

Pierce E, Xie G, Barabote RD et al (2008) The complete genome sequence of Moorella thermoacetica (f. Clostridium thermoaceticum). Environ Microbiol 10:2550-2573

Pilloni G, von Netzer F, Engel M, Lueders T (2011) Electron acceptor-dependent identification of key anaerobic toluene degraders at a tar-oil-contaminated aquifer by Pyro-SIP. FEMS Microbiol Ecol 78:165-175

Pilloni G, Granitsiotis MS, Engel M, Lueders T (2012) Testing the limits of 454 pyrotag sequencing: reproducibility, quantitative assessment and comparison to T-RFLP fingerprinting of aquifer microbes. PLoS ONE 7:e40467

Plugge CM, Balk M, Stams AJM (2002) Desulfotomaculum thermobenzoicum subsp thermosyntrophicum subsp nov., a thermophilic, syntrophic, propionate-oxidizing, sporeforming bacterium. Int J Syst Evol Microbiol 52:391-399

Poulton SW (2003) Sulfide oxidation and iron dissolution kinetics during the reaction of dissolved sulfide with ferrihydrite. Chem Geol 202:79-94

Robertson WJ, Bowman JP, Franzmann PD, Mee BJ (2001) Desulfosporosinus meridiei sp nov., a spore-forming sulfate-reducing bacterium isolated from gasolene-contaminated groundwater. Int J Syst Evol Microbiol 51:133-140

Safinowski M, Meckenstock RU (2004) Enzymatic reactions in anaerobic 2-methylnaphthalene degradation by the sulphate-reducing enrichment culture N 47. FEMS Microbiol Lett 240:99-104

Selesi D, Meckenstock RU (2009) Anaerobic degradation of the aromatic hydrocarbon biphenyl by a sulfate-reducing enrichment culture. FEMS Microbiol Ecol 68:86-93

Stuart M, Lapworth D, Crane E, Hart A (2012) Review of risk from potential emerging contaminants in UK groundwater. Sci Total Environ 416:1-21 
Sullivan ER, Zhang XM, Phelps C, Young LY (2001) Anaerobic mineralization of stable-isotope-labeled 2-methylnaphthalene. Appl Environ Microbiol 67:4353-4357

Suzek BE, Huang H, McGarvey P, Mazumder R, Wu CH (2007) UniRef: comprehensive and non-redundant UniProt reference clusters. Bioinformatics 23:1282-1288

Thamdrup B, Finster K, Hansen JW, Bak F (1993) Bacterial disproportionation of elemental sulfur coupled to chemical reduction of iron or manganese. Appl Environ Microbiol 59:101-108

Tindall BJ, Rossello-Mora R, Busse HJ, Ludwig W, Kampfer P (2010) Notes on the characterization of prokaryote strains for taxonomic purposes. Int $\mathrm{J}$ Syst Evol Microbiol 60:249-266

Villemur R, Lanthier M, Beaudet R, Lepine F (2006) The Desulfitobacterium genus. FEMS Microbiol Rev 30:706-733

Wang Q, Garrity GM, Tiedje JM, Cole JR (2007) Naive Bayesian classifier for rapid assignment of rRNA sequences into the new bacterial taxonomy. Appl Environ Microb 73:5261-5267

Weelink SAB, van Doesburg W, Saia FT, Rijpstra WIC, Roling WFM, Smidt H, Stams AJM (2009) A strictly anaerobic betaproteobacterium Georgfuchsia toluolica gen. nov., sp nov degrades aromatic compounds with $\mathrm{Fe}(\mathrm{III}), \mathrm{Mn}(\mathrm{IV})$ or nitrate as an electron acceptor. FEMS Microbiol Ecol 70:575-585

Widdel F and Bak F (1991) Gram-negative mesophilic sulfatereducing bacteria. In: Balows A, Trüper HG, Dworkin M, Harder W and Schleifer KH (eds) The prokaryotes. Springer, New York, pp 3352-3378

Yoneda Y, Yoshida T, Yasuda H, Imada C, Sako Y (2013) A thermophilic, hydrogenogenic and carboxydotrophic bacterium, Calderihabitans maritimus gen. nov., sp nov., from a marine sediment core of an undersea caldera. Int J Syst Evol Microbiol 63:3602-3608

Zhang X, Young L (1997) Carboxylation as an initial reaction in the anaerobic metabolism of naphthalene and phenanthrene by sulfidogenic consortia. Appl Environ Microbiol 63:4759-4764

Zhang CLL, Li YL, Ye Q et al (2003) Carbon isotope signatures of fatty acids in Geobacter metallireducens and Shewanella algae. Chem Geol 195:17-28

Zhang DC, Mortelmaier C, Margesin R (2012a) Characterization of the bacterial archaeal diversity in hydrocarboncontaminated soil. Sci Total Environ 421:184-196

Zhang T, Bain TS, Nevin KP, Barlett MA, Lovley DR (2012b) Anaerobic benzene oxidation by Geobacter species. Appl Environ Microbiol 78:8304-8310 